screen (from those with history of in-utero exposure) were significant predictors for onset of NAS requiring pharmacological intervention at $>96 \mathrm{HOL}$ (OR 0.21 ; p value 0.011 ).

Conclusions The majority of infants who required pharmacological treatment for NAS during their postnatal observation period were diagnosed within the first $120 \mathrm{HOL}$. Those atrisk infants, born to mothers with a known history of exposure, who have a negative urine toxicology screen for both baby and mother, should be monitored beyond 5 days as they tend to have a later presentation.

\section{OC64 STETHAID: MOBILE TECHNOLOGY FOR SMART AUSCULTATION IN CHILDREN}

'Layla Taryam, ${ }^{1}$ Sumaya AL Zarooni, ${ }^{1}$ Olfat Alzaabi, ${ }^{1}$ Asif Afridi, 'Zainab Abdullah, ${ }^{1}$ Amrish Kumar Kumar, ${ }^{1}$ Mohamed Ali Ali, 'Moza Khalaf, ${ }^{2}$ Titus John, ${ }^{2}$ Ravi T Ambati, ${ }^{2}$ Robin W Doroshow, ${ }^{2}$ Raj Shekhar, ${ }^{1}$ Asma Alzumar*. 'Ministry of Health and Prevention, Dubai, UAE; ${ }^{2}$ Children's National Health System, Washinton, DC, USA

10.1136/archdischild-2019-epa.61

Innocent heart murmurs occur in approximately half of healthy children at some point in their childhood. Still's murmur is the most prevalent of these innocent pediatric heart murmurs with a prevalence of approximately $40 \%$. Auscultation remain the primary clinical tool utilized to identify Still's murmur from the murmurs of true heart disease. However, general physicians (GPs) are not successful in distinguishing a Still's murmur from pathological murmurs and therefore refer a large number of children to pediatric cardiologists. Besides cost and inconvenience, these referrals are a source of extreme anxiety and stress in children and families while waiting to see a pediatric cardiologist. Our objective has been to develop a novel technology that can help a GP classify a Still's murmur with high accuracy at the point of care and support their decisions regarding referral to a specialist. We have created a stethoscope that connects to a smartphone and developed a custom mobile application that records heart sounds and, using machine learning, analyzes them for the presence of a Still's murmur. This solution is called StethAid. The algorithm to identify Still's murmur has been developed and tested utilizing a pediatric heart murmur library of over 1800 patients with clinically documented diagnoses compiled at Children's National Health System. Using StethAid, we recorded heart sounds of 312 pediatric patients at two UAE Ministry of Health and Prevention hospitals to be utilized as an independent test set. The algorithm identifies Still's murmur with a sensitivity of $89 \%$ and specificity of $97 \%$. The proposed technology could potentially lower the current high rate of referrals to pediatric cardiologists associated with Still's murmur.

\section{OC65 NORMATIVE NEONATAL FACIAL BIO-METRICS IN THE UNITED ARAB EMIRATES FOR NON-INVASIVE EARLY DETECTION OF GENETIC DISORDER}

${ }^{1}$ Olfat Al Zaabi*, ${ }^{2}$ Antonio R Porras, 'Safyia Saif Al Khajeh, 'Yamen El Moghanni, ${ }^{1}$ Mona Salah, ${ }^{1}$ Ahmed Abdelwahab Ismail, ${ }^{1}$ Asma Abdelrahman Al Mazar, ${ }^{1}$ Mona Abdul Rahman, ${ }^{1}$ Rola Helmi, 'Luay A Wahab, ${ }^{1}$ Hussein Eleimy, ${ }^{1}$ Anshad Ummerkhan, ${ }^{2}$ Marius George Linguraru. 'Ministry of Health and Prevention, Dubai, UAE; ${ }^{2}$ Children's National Health System, Washington, DC, USA

10.1136/archdischild-2019-epa.62
Perinatal identification of genetic syndromes with facial dysmorphology is challenging due to subtle manifestations and population variability. Recent studies have shown that genetic syndromes manifest differently on populations of different ancestries. The purpose of this study is to quantify the distribution of facial biometrics of healthy newborns among the local population of the United Arab Emirates. In this first study of its kind, we collected frontal facial pictures from 504 healthy newborns without facial dysmorphology (252 males and 252 females, age range 0-4 days, gestational age at birth range 37-42 weeks) between October 2015 and March 2017 at hospitals in the network of the United Arab Emirates Ministry of Health and Prevention: Al Qassimi Hospital in Sharjah and Fujairah Hospital. We measured a set of distances and angles between facial landmarks on the eyes, nose and mouth in all pictures. Horizontal and vertical distances were normalized as a percentage with respect to the distance between lateral canthi and the eye-to-mouth distance, respectively. The average axes of the palpebral fissures were $27 \pm 3 \%$ and $9 \pm 3 \%$. The distance between the medial canthi was $47 \pm 4 \%$. The average angle between each medial canthus with respect to the corresponding lateral cathus and the other medial canthus - a measure of slanting of the eyes-was $176 \pm 4$ degrees. The distance between the oral comissures was $48 \pm 6 \%$. The nose length was $35 \pm 8 \%$. This first normative reference of facial biometrics in newborns in the United Arab Emirates has great potential to support the perinatal identification of genetic conditions through quantitative facial analysis.

\section{OC66 SUCCESSFUL PILOT INTRODUCTION OF A 'VIRTUAL CLINIC' FOR A REGIONAL COHORT OF PATIENTS WITH TYPE 1 DIABETES}

${ }^{1}$ Anne Quinn, ${ }^{1}$ Therese Dunne, ${ }^{1,2}$ Clodagh O'Gorman, ${ }^{2}$ Niall Collins, ${ }^{1}$ Orla Neylon*. ${ }^{1}$ University Hospital Limerick, Limerick, Ireland; ${ }^{2}$ GEMS Medical School, UL, Limerick, Ireland

\subsection{6/archdischild-2019-epa.63}

Background Among Irish paediatric centres, 30\% are not meeting the recommendation of three-monthly review of patients with Type 1 Diabetes (T1D). ${ }^{1}$ Long waiting times are encountered by our patient cohort at out-patient clinics, along with a sometimes passive approach to reflective dose adjustment. We wished to explore the feasibility of a targeted educational intervention using a 'virtual clinic' in a sample of our population, given the well-described challenges with rural broadband provision in the West of Ireland.

Aim Primary outcome was the proportion of successfully completed internet 'virtual clinic' appointments with participants, including successful pre-clinic download of insulin pump data. Secondary outcomes included setting adjustments, impact on glycaemic control, appointment duration and user satisfaction, the latter by qualitative survey.

Methods Participants using insulin pumps and continuous glucose monitoring systems were recruited from out-patients. Intervention consisted of 3 'virtual clinic' sessions at 10-14 day intervals using 'Skype for Business@)' to connect the diabetes team with the family in their home. Data were collated in Excel, with postal HbA1c. 
Results Sixteen patients were approached, of which 10 participants were recruited, with IT issues precluding participation in $30 \%$. Of the 24 virtual clinic sessions, 21 (88\%) were successful. Mean age of participants was $11.9 \pm 3.3$ years with a mean duration of diabetes of $5.5 \pm 3.2$ years. Mean duration of clinic appointments decreased over time from 30 to 23 mins $(p=0.04)$ with an average of 4 setting changes per appointment. Mean HbA1c decreased from 7.8\% (62 $\mathrm{mmol} / \mathrm{mol})$ pre-intervention to $7.6 \% \quad(60 \mathrm{mmol} / \mathrm{mol})$ just afterwards, with a sustained decrement to $7.2 \% \quad(55 \mathrm{mmol} /$ $\mathrm{mol})$ at 6 months post-intervention $(p=0.005)$. Satisfaction was rated as excellent by $100 \%$ of participants, with $100 \%$ wishing for such a service to be a continued part of their child's care.

Conclusion This prospective observational cohort study showed that connection by 'virtual clinic' is feasible in rural Ireland, with high rates of user satisfaction and a positive impact on overall glycaemic control of participants.

\section{REFERENCE}

1. Hawkes C, Murphy NP. Paediatric type 1 diabetes in Ireland-results of the first national audit. Ir Med J 2014 April;107(4):102-4.

\section{OC67 CAREER SATISFACTION AMONG PEDIATRIC RESIDENTS IN TWO EUROPEAN COUNTRIES (IRELAND AND TURKEY): A COMPARATIVE STUDY}

\begin{abstract}
${ }^{1}$ Busra Nukhet Pehlivanoglu* ${ }^{2}$ Sarah Lewis, ${ }^{1}$ Nisa Pekcan Bolukbasi, ${ }^{2}$ Michael Fitzgerald, ${ }^{3}$ Ozden Aksu Sayman, ${ }^{4}$ Michelle Bradbury, ${ }^{5}$ Anne Marie Murphy, ${ }^{6}$ Gulnaz Cig, ${ }^{5}$ Ellen Crushell. ${ }^{1}$ Istanbul University Cerrahpasa, Faculty of Medicine, Department of pediatric, Istanbul, Turkey; ${ }^{2}$ Royal College of Physicians in Ireland and EURYPA, Dublin, Ireland; ${ }^{3}$ Istanbul Haydarpasa Numune Training and Research Hospital, Istanbul, Turkey; ${ }^{4}$ University of Limerick, Limerick, Ireland; ${ }^{5}$ Royal College of Physicians in Ireland, Dublin, Ireland; ${ }^{6}$ Istanbul University Cerrahpasa, Faculty of Medicine, Department of Public Health, Istanbul, Turkey
\end{abstract}

\subsection{6/archdischild-2019-epa.64}

Aim The aim of this study was to conduct a nationwide evaluation of career satisfaction and training experience among residents in pediatrics in both Ireland and Turkey.

Patients and methods Questionnaires were designed by the authors and distributed electronically in Turkey to paediatric residents. The same questionnaire was translated to English and distributed to pediatric residents in Ireland in paper format. Data was collected on demographics (age, gender), characteristics of training institution, exposure to physical or psychological violence, average number of night shifts per month and usage of antidepressants and was analysed using SPSS. Five hundred residents $(332$ (66.4\%) female, 168 $(33.6 \%)$ male) in Turkey and sixty-one residents (46 (75.4\%) female, $15(24.6 \%)$ male) in Ireland completed the questionnaire.

Results Resident satisfaction was approximated using a composite score of academic and professional satisfaction. Resident satisfaction was rated higher in Ireland than in Turkey $(\mathrm{p}<0.001)$ with $42(68.9 \%)$ participants in Ireland and 138 (27.6\%) participants in Turkey satisfied with their training when analysed by this method.Four hundred (80\%) Turkish residents and 33 (54.1\%) Irish residents had considered resigning one or more times during their training, which represented a significant difference between the two countries $(p<0.01)$. The average number of night shifts per month for Turkish and Irish residents was 7.37 and 4.44 respectively $(\mathrm{p}<0.001)$. Turkish residents were more likely to be taking antidepressant medication at the time of the survey $(12.4 \%$ Turkish residents vs. $1.6 \%$ Irish residents, $\mathrm{p}<0.001)$. One-hundred and thirteen residents (22.6\%) in Turkey and eleven $(18 \%)$ residents in Ireland were subjected to physical violence by patients and/or relatives $(\mathrm{p}=0.08)$. Four hundred sixtyseven (93.4\%) Turkish residents and thirty-eight (62.3\%) Irish residents were exposed to psychological violence $(\mathrm{p}<0.001)$. There was no significant difference between sex, marital status, living alone, having a child or duration of training $(\mathrm{p}>0.05)$

Conclusion This international comparative study describes a wide variation in the level of career satisfaction among residents in pediatrics. Irish residents were reportedly more satisfied with training, less likely to have considered resigning from residency, worked fewer night shifts, reported lower rates of antidepressant use and less exposure to violence at work than their Turkish peers. Regional, cultural and social factors as well as variation in working conditions may impact resident satisfaction. Measures such as reducing frequency of night shifts and support from occupational health may improve resident experience. Collaboration between national training organisations may inspire ideas for positive change.

\section{OC68 THE BACKPACK WEIGHTS OF PRIMARY SCHOOL STUDENTS AND THEIR BACKPACK USE STATUS}

Tufan Aslı Sezer, Aslıhan Öztürk, Figen Işık Esenay*. Ankara University Faculty of Nursing, Ankara, Turkey

\subsection{6/archdischild-2019-epa.65}

Objective Inappropriate backpack use may cause several health problems in children such as shoulder, waist, back pain and postural disorders. These problems reduce the quality of life of children and affect their success in their educational lives. The aim of this study was to determine the usage and weight of backpacks carried by primary school children.

Method This descriptive cross-sectional study was carried out in fall semester of 2016-2017 academic year. The sample of the study consisted of 374 students aged between 6-11 years, selected by random sampling method from three different public primary schools in Ankara, the capital city of Turkey. Data was gathered a personal information form and ideal backpack usage checklist based on literature. Descriptive statistics, independent $t$ test and one way ANOVA were used for data analysis.

Results $53.9 \%$ of the children participating in the study were male, the mean age was $8.33 \pm 1.32$ years. The mean backpack weight was $4.03 \mathrm{~kg}$ and represented $14.4 \%$ of their body weight. $96.2 \%$ of them carried backpacks with both straps, $54.2 \%$ of the backpacks had not full contact with their backs, $42.1 \%$ of the backpacks stands below on their back and none of them using a waist belt. As children aged and classes increased, the weight of carrying bag increased $(\mathrm{p}<0.01)$.

Conclusion The result of this study indicated that the children of primary schools carried backpacks heavier than $10 \%$ of their body weights and had inappropriate backpack usage. The results show the necessity of taking measures for appropriate backpack use and informing children, families and teachers. 